\title{
Variations in water storage in China over recent decades from GRACE observations and GLDAS
}

\author{
X. Mo, J. J. Wu, Q. Wang, and H. Zhou \\ Academy of Disaster Reduction and Emergency Management, MOCA/MOE, Beijing Normal University, \\ Beijing 100875, China \\ Correspondence to: J. J. Wu (jjwu@bnu.edu.cn)
}

Received: 7 January 2015 - Published in Nat. Hazards Earth Syst. Sci. Discuss.: 11 May 2015

Revised: 18 December 2015 - Accepted: 14 January 2016 - Published: 17 February 2016

\begin{abstract}
We applied Gravity Recovery and Climate Experiment (GRACE) Tellus products in combination with Global Land Data Assimilation System (GLDAS) simulations and data from reports, to analyze variations in terrestrial water storage (TWS) in China as a whole and eight of its basins from 2003 to 2013. Amplitudes of TWS were well restored after scaling, and showed good correlations with those estimated from models at the basin scale. TWS generally followed variations in annual precipitation; it decreased linearly in the Huai River basin $\left(-0.56 \mathrm{~cm} \mathrm{yr}^{-1}\right)$ and increased with fluctuations in the Changjiang River basin $\left(0.35 \mathrm{~cm} \mathrm{yr}^{-1}\right)$, Zhujiang basin $\left(0.55 \mathrm{~cm} \mathrm{yr}^{-1}\right)$ and southeast rivers basin $\left(0.70 \mathrm{~cm} \mathrm{yr}^{-1}\right)$. In the Hai River basin and Yellow River basin, groundwater exploitation may have altered TWS's response to climate, and TWS kept decreasing until 2012. Changes in soil moisture storage contributed over $50 \%$ of variance in TWS in most basins. Precipitation and runoff showed a large impact on TWS, with more explained TWS in the south than in the north. North China and southwest rivers region exhibited long-term TWS depletions. TWS has increased significantly over recent decades in the middle and lower reaches of Changjiang River, southeastern coastal areas, as well as the Hoh Xil, and the headstream region of the Yellow River in the Tibetan Plateau. The findings in this study could be helpful to climate change impact research and disaster mitigation planning.
\end{abstract}

\section{Introduction}

Terrestrial water storage (TWS) is a key component of the global hydrological cycle and plays a critical role in Earth's climate system (Famiglietti, 2004). Despite its importance, there are still many gaps in the existing water storage observation networks at both the global and regional scale (Lettenmaier and Famiglietti, 2006). Although recent advances in satellite imaging and altimetry have strengthened our monitoring capability over a vast area, these technologies primarily provide only variation information for single factors related to TWS, such as precipitation estimates, surface soil moisture, snow cover, and river/lake level. With the progress in satellite gravimetric techniques, direct observation of TWS has become available. The Gravity Recovery and Climate Experiment (GRACE) twin satellites were launched in 2002 as a joint space mission between NASA (US) and DLR (German) to observe variations in Earth's gravity field. Over land, these observations provide information of integrated water storage changes in the vertical profile, including surface water reservoirs, upper layers of soil, and underground water reservoirs.

At global, regional, and basin scale, GRACE data have been applied to analyze seasonal cycle characteristics of TWS (Schmidt et al., 2006; Syed et al., 2008; Strassberg et al., 2007). Because of their sensitivity to water amount over large areas, GRACE data can also be a useful tool for identifying impact caused by extreme climate events like droughts and floods, or for tracking climate change's influence on local water resources (Andersen et al., 2005; Long et al., 2013; Phillips et al., 2012). Scientists found that inclusion of GRACE-based total water storage information allows the predisposition of a river basin to flooding to be assessed as much as 5-11 months in advance (Reager et al., 2014). Chen et al. $(2009,2010)$ quantified an extreme drought in 2005 and an extreme flood in 2009 in the Amazon river, 
and found that local interannual TWS changes are closely connected to ENSO events in the tropical Pacific. Because of the lack of direct observations independent of GRACE TWS, TWS estimated from the atmospheric water balance, land water balance, and model simulations was used to compare with and verify the GRACE TWS (Yirdaw et al., 2008; Zeng et al., 2008; Syed et al., 2005; Schmidt et al., 2006). These papers have demonstrated that GRACE data are capable of identifying seasonal and long-term variations in TWS and have also made contributions to the development of climate and hydrological models.

GRACE TWS combined with hydrological information from other observations or models could help us further understand and manage variables in the hydrological cycle. Land surface model simulations were used to infer the roles of water components (snow water, canopy water, and soil water) in GRACE terrestrial water storage change (TWSC) and to understand the effect of hydrologic fluxes fluctuation on water storage (Syed et al., 2008; Kim et al., 2009). With the help of TRMM data and NOAA's Climate Prediction Center (CPC) model simulations, Crowley et al. (2008) found that the source (precipitation) is more important than sink (evapotranspiration and runoff) to the water balance in the Amazon basin. Other papers tried to separate variations in groundwater storage from GRACE TWS, and their results showed agreement with in situ observations (Rodell et al., 2009; Leblanc et al., 2009; Famiglietti et al., 2011; Jin and Feng, 2013).

In China, GRACE data have been compared with several model simulations and used to extract TWS's spatial and temporal variation characteristics as well as its responses to droughts (Duan et al., 2007; Zhong et al., 2009; Wang and Yang, 2013; Hu et al., 2006; Xu et al., 2013; Tang et al., 2013, 2014). The serious TWS depletion in north China has gained much attention in recent years (Su et al., 2011; Moiwo et al., 2009; Feng et al., 2013). Previous research has mostly focused on characteristics of the seasonal cycle in TWS in certain regions, and there has been less further analysis of long-term variations over China. Moreover, early research was typically limited by the short period of data availability and the obsolete version, and leakage errors in TWS from processed GRACE data could also misguide analyses at the regional scale.

China is one of the countries that is confronted with problems of water scarcity and has suffered several regional extreme climate events in recent decades. The knowledge of TWS variations over recent decades is necessary for understanding the large-scale water storage variation process. In this study, the GRACE Tellus land products and Global Land Data Assimilation System (GLDAS) products, combined with data records from national water resources bulletins, were used to analyze long-term TWS variations in China as a whole, as well as in its eight major basins. This study could give guidance to water resource management and future research on areas with critical water storage changes in China. For better understanding, main acronyms and variables used in this paper are listed in Table 1.

\section{Data and methods}

\subsection{Data}

The monthly grids from GRACE Tellus land data are applied to analyze TWS variations. The product is derived from the latest Release-05 spherical harmonics, which is an improvement over the previous 04 version. Several institutions provide gravity solutions, such as the University of Texas Center for Space Research (CSR), NASA's Jet Propulsion Laboratory (JPL), and Deutsches GeoForschungsZentrum (GFZ). A recent comparison suggested that TWS estimates from GFZ, CSR, and JPL solutions were highly correlated with one other, and tiny differences among them were within the margin of solution's error (Sakumura et al., 2014). Among these three products, the one from CSR had the smallest root-mean-square (RMS) of deviations between the ensemble mean and itself in 156 basins around the world. In this study, we chose products derived from CSR's solution for the following analyses. The paper by Swenson and Wahr (2006) describes the details of the post-processing for the spherical harmonics. The final grid $\left(1^{\circ}\right.$ in both latitude and longitude) values are presented in the form of changes in equivalent water thickness (unit: $\mathrm{cm}$ ) relative to a time-mean baseline. The data period is from January 2003 to December 2013 and months of absent data are as follows: June 2003, January and June 2011, May and October 2012, and March, August, and September 2013. Grid-scale factors, which correspond to the gridded product, were used to partially correct leakage errors and restore the amplitude-damping caused by the filtering process. Errors and uncertainties in mass variation can be computed from the scaled gridded data (Launderer and Swenson, 2012). In this paper, gridded fields of scale factors and error estimates provided along with the GRACE Tellus products were calculated following Landerer's method based on NCAR's CLM4 model (Oleson et al., 2008). Recently, Long et al. (2015) conducted comprehensive comparisons to assess skills and uncertainties of different approaches for processing GRACE data to restore signal losses caused by spatial filtering.

Monthly flux/state variables (Table 2) from GLDAS (Rodell et al., 2004) were applied to estimate water storage variations, and these variables were also used to address variations in the components of water storage. GLDAS drives four land surface models: Mosaic (Koster and Suarez, 1996), Noah (Chen et al., 1996; Koren et al., 1999; Betts et al., 1997; Ek et al., 2003), Community Land Model (CLM) (Bonan et al., 1998; Dickinson et al., 1993; Dai and Zeng, 1997), and Variable Infiltration Capacity (VIC) (Liang et al., 1994, 1996). Satellite-based and ground-based observations are integrated into these models to generate optimal fields of land 
Table 1. List of main acronyms and variables used in the paper.

\begin{tabular}{ll}
\hline $\begin{array}{l}\text { Acronym/ } \\
\text { variable }\end{array}$ & Full name \\
\hline GRACE & Gravity Recovery and Climate Experiment \\
NASA & National Aeronautics and Space Administration \\
DLR & Deutsches Zentrum für Luft- und Raumfahrt \\
CSR & University of Texas, Center for Space Research \\
JPL & Jet Propulsion Laboratory \\
GFZ & Deutsches GeoForschungsZentrum \\
CMAP & Climate Prediction Center Merged \\
& Analysis of Precipitation \\
CPC & Climate Prediction Center \\
CMA & China Meteorological Administration \\
GLDAS & Global Land Data Assimilation System \\
CLM & Community Land Model \\
VIC & Variable Infiltration Capacity model \\
PDF & Probability density function \\
RMS & Root-mean-square \\
TWS & Terrestrial water storage \\
TWSC & Terrestrial water storage change \\
SWE & Snow water equivalent \\
CWS & Canopy water storage \\
SM & Soil moisture \\
$P$ & Precipitation \\
$E$ & Evapotranspiration \\
$Q$ & Runoff \\
\hline
\end{tabular}

Table 2. Variables used from the GLDAS simulations.

\begin{tabular}{llll}
\hline GLDAS variables & Unit & $\begin{array}{l}\text { Temporal } \\
\text { resolution }\end{array}$ & $\begin{array}{l}\text { Spatial } \\
\text { resolution }\end{array}$ \\
\hline Soil moisture (SM) & $\mathrm{kg} \mathrm{m}^{2}$ & Monthly & $1^{\circ} \times 1^{\circ}$ \\
Snow water equivalent (SWE) & $\mathrm{kg} \mathrm{m}^{2}$ & Monthly & $1^{\circ} \times 1^{\circ}$ \\
Canopy water storage (CWS) & $\mathrm{kg} \mathrm{m}^{2}$ & Monthly & $1^{\circ} \times 1^{\circ}$ \\
Precipitation $(P)$ & $\mathrm{kg} \mathrm{m}^{-2} \mathrm{~s}^{-1}$ & Monthly & $1^{\circ} \times 1^{\circ}$ \\
Evapotranspiration $(E)$ & $\mathrm{kg} \mathrm{m}^{-2} \mathrm{~s}^{-1}$ & Monthly & $1^{\circ} \times 1^{\circ}$ \\
Runoff $(Q)$ & $\mathrm{kg} \mathrm{m}^{-2} \mathrm{~s}^{-1}$ & Monthly & $1^{\circ} \times 1^{\circ}$ \\
\hline
\end{tabular}

surface states and fluxes. The forcings for these models from 2001 to present are a combination of NOAA/GDAS atmospheric analysis fields, spatially and temporally disaggregated NOAA Climate Prediction Center Merged Analysis of Precipitation (CMAP) fields (Xie and Arkin, 1996) and observation-based downward shortwave and long-wave radiation fields from the Air Force Weather Agency (AFWA).

Drainage networks are mostly distributed in the monsoondominated middle and east China (Fig. 1a), which are also highly populated areas with high levels of water consumption. In this study, we specifically focus on eight large basins: Heilongjiang River, Liao River, Hai River, Huai River, Yellow River, Changjiang River, Zhujiang, southeast rivers (with abbreviations of HLJ, LR, HaiR, HuaiR, YR, CJ, ZJ, and SERs, respectively, in the following tables). Desert is the dominant land cover in northwestern China, while glacier, snow cover, and frozen soil are widely distributed across the Tibetan Plateau (Fig. 1b). Vector data for the desert are acquired from the Data Sharing Infrastructure of Earth Sys- tem Science (http://www.geodata.cn). The Second Glacier Inventory Dataset of China (Version 1.0) is acquired from Science Data Center for Cold and Arid Regions (http:// westdc.westgis.ac.cn). Annual Chinese water resources bulletins from 2003 to 2012 are acquired from the Ministry of Water Resources to assist with the analysis. Values for surface water resources, groundwater resources and gross water resources provided in the water resources bulletins are the results of existing monitoring and statistical analyses (Fig. 5). Surface water resources refer to water storage in rivers, lakes, and glaciers, and groundwater resources mainly refer to water storage in underground shallow aquifers.

\subsection{Methods}

\subsubsection{Data preprocessing}

Unlike scale factor applied for region-averaged TWS time series in previous research (Chen et al., 2007; Landerer et al., 2010; Feng et al., 2013), monthly products from GRACE Tellus land data were multiplied by grid-scale factors to restore signal attenuation. Next, the average value for each grid from Janunary in 2003 to December 2013 was subtracted from all other scaled monthly grids. The deviations to timeaveraged TWS were used for the following analyses. At the regional scale, all grids in a basin were averaged with the cosine of latitude as the weight, and missing values for absent months were interpolated from adjacent available months. For regionally averaged TWS, total errors were calculated from error fields provided along with the GRACE products (Eqs. 1, 2, Table 5). Because of spatial correlation among neighboring grids, covariance was considered in the calculation of regional-scale error Error ${ }_{\text {region }}$ (Landerer and Swenson, 2012; Eq. 1). The dist in Eq. (1) is the geometric distance between any two grids in the basin (unit: $\mathrm{km}$ ); $n$ is the number of valid grids in a specific basin; $\beta$ is the de-correlation length, which is set to 300 for measurement error and 100 for leakage error; $i$ and $j$ indicate the value in the $i$ th column and $j$ th row of the grid data. The regional-scale total error Error ${ }_{\text {total }}$ included both regional-scale measurement er-

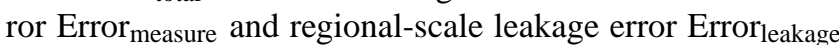
(Eq. 2). Early analysis suggested that the TWS variations could be distinguished from GRACE monthly data over regions larger than $200000 \mathrm{~km}^{2}$, with an accuracy of $1.5 \mathrm{~cm}$ equivalent water thickness (Rodell and Famiglietti, 1999), and the larger the spatial scale of the research area was, the better the accuracy the results could acquire (Swenson and Wahr, 2003; Wahr et al., 2004).

$$
\begin{aligned}
\text { Error }_{\text {region }} & =\sqrt{\sum_{i=1}^{n} \sum_{j=1}^{n} \text { Error }_{i} \cdot \text { Error }_{j} \cdot e^{-\left(\text {dist }_{i, j}^{2}\right) /\left(2 \cdot \beta^{2}\right)}} / n \\
\text { Error }_{\text {total }} & =\sqrt{\left(\text { Error }_{\text {measure }}\right)^{2}+\left(\text { Error }_{\text {leakage }}\right)^{2}}
\end{aligned}
$$

State variables (snow water equivalent, SWE; canopy water storage, CWS; total soil moisture storage in all layers, SM) 

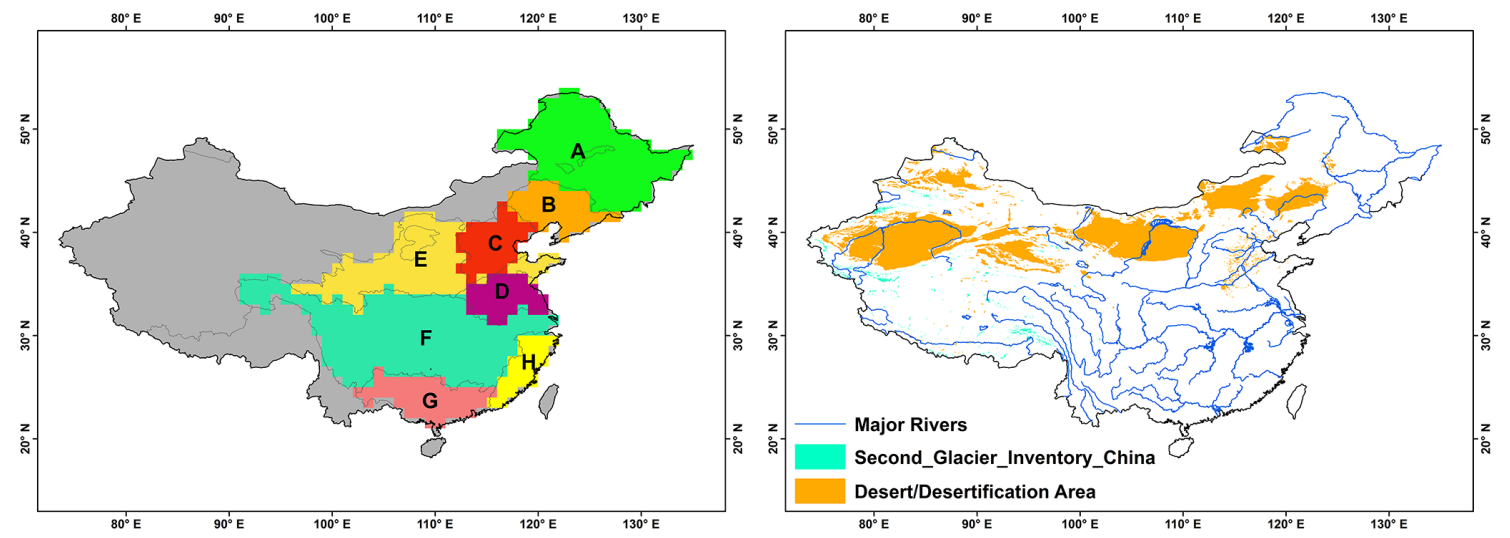

Figure 1. Schematic diagrams of research area (A: Heilongjiang River, B: Liao River, C: Hai River, D: Huai River, E: Yellow River, F: Changjiang River, G: Zhujiang, H: southeast rivers).

and flux variables (precipitation, $P$; evapotranspiration, $E$; runoff, $Q$ ) from the four models in GLDAS were presented in the form of equivalent water thickness (unit: $\mathrm{cm}$ ). The time averages were removed from these variables following the process used for the GRACE data to keep the same time base for comparison. The ensemble mean (arithmetic average) of the four models' simulations was also calculated to be used as the representative of model results.

\subsubsection{TWS estimates from model simulations}

In despite of deficiencies in model simulations, state variables SWE, CWS, and SM from GLDAS outputs can be combined to estimate TWS (Eq. 3). Although the estimates are not able to fully reflect the information in the actual TWS variations, they can still capture the fluctuation and magnitude in land hydrology, which is necessary for assessing and understanding the TWS observation from GRACE (Syed et al., 2004).

$\mathrm{TWS}=\mathrm{SWE}+\mathrm{CWS}+\mathrm{SM}$

Pearson correlation coefficients $R$ between TWS from scaled GRACE and model simulations are listed in Table 3. TWS estimates from CLM and VIC have relatively poor correlations with GRACE observations at the national scale. However, all model estimates generally have high correlation coefficients at the regional scale, except in the Heilongiiang River basin. The differences between models and regions showed that model simulations have a high degree of uncertainties, and TWS estimates from NOAH and the GLDAS ensemble mean have a good agreement with TWS from scaled GRACE at both the national and regional scale. The differences between the GLDAS simulations and the GRACE observations are mainly the result of missing information on components of land hydrology, such as groundwater and reservoirs, and poor parameterization (snow cover, frost soil, etc.) in the model mechanism (Syed et al., 2008). These components or processes could be critical to TWS in some parts
Table 3. Pearson correlation coefficients $r$ between regionally averaged TWS from the scaled GRACE data and model simulations in China as a whole and eight of its basins.

\begin{tabular}{llllll}
\hline Region & CLM & VIC & MOSAIC & NOAH & $\begin{array}{l}\text { Ensemble } \\
\text { mean }\end{array}$ \\
\hline HLJ & 0.83 & 0.84 & 0.74 & 0.87 & 0.86 \\
LR & 0.71 & 0.65 & 0.54 & 0.64 & 0.64 \\
HaiR & 0.43 & 0.54 & 0.66 & 0.61 & 0.61 \\
HuaiR & 0.68 & 0.54 & 0.68 & 0.79 & 0.72 \\
YR & 0.77 & 0.62 & 0.62 & 0.70 & 0.69 \\
CJ & 0.61 & 0.51 & 0.47 & 0.77 & 0.60 \\
ZJ & 0.70 & 0.77 & 0.79 & 0.82 & 0.81 \\
SERs & 0.70 & 0.69 & 0.83 & 0.76 & 0.81 \\
CHN & 0.25 & 0.31 & 0.53 & 0.79 & 0.55 \\
\hline
\end{tabular}

Table 4. Error statistics of regionally averaged TWS (unit: $\mathrm{cm}$ ).

\begin{tabular}{llllll}
\hline Region & $\begin{array}{l}\text { Area } \\
\left(\mathrm{km}^{2}\right)\end{array}$ & $\begin{array}{l}\text { Measurement } \\
\text { error }\end{array}$ & $\begin{array}{l}\text { Leakage } \\
\text { error }\end{array}$ & $\begin{array}{l}\text { Total } \\
\text { error }\end{array}$ & $\begin{array}{l}\text { Bias for } \\
\text { GLDAS }\end{array}$ \\
\hline China & 9510610 & 0.38 & 0.31 & 0.54 & 0.63 \\
Changjiang River & 1815855 & 0.90 & 0.79 & 1.27 & 1.47 \\
Heilongjiang River & 956832 & 0.98 & 0.72 & 1.39 & 1.10 \\
Yellow River & 860883 & 0.78 & 0.73 & 1.10 & 0.72 \\
Zhujiang & 463050 & 1.86 & 1.62 & 2.63 & 3.35 \\
Hai River & 327096 & 1.30 & 1.36 & 1.84 & 1.59 \\
Liao River & 310881 & 1.13 & 0.98 & 1.60 & 1.61 \\
Huai River & 288152 & 1.74 & 1.54 & 2.46 & 3.51 \\
Southeast rivers & 242524 & 1.44 & 1.29 & 2.04 & 3.69 \\
\hline
\end{tabular}

of the world (Rodell and Famiglietti, 2001). The RMS of deviations from the ensemble mean was calculated as the bias of TWS estimates from the GLDAS simulations (Table 4).

\subsubsection{Scaling effect assessment}

To understand how many changes scale factors could make to GRACE TWS in China, we compared the spatial distributions of the amplitude of TWS variations from observations 
and simulations. The RMS of the time series at each grid was taken as a proxy for local TWS amplitude, and then the empirical probability density functions (PDFs) for RMS values over China were calculated for TWS derived from scaled and unscaled GRACE data and the model simulations. To avoid abnormal values, only RMS values between the 5th and 95th quantile over China were considered. For regionally averaged TWS, the slopes and coefficients of determination $R^{2}$ were calculated with a linear least squares fit to assess the damping influence of leakage errors (Eq. 4).

$\mathrm{TWS}_{\text {scaled }}=a \cdot \mathrm{TWS}_{\text {unscaled }}$

\subsubsection{Analysis of TWS long-term variations}

TWSC, the integrated changes in the vertical components of TWS, is the difference between current and previous months' TWS (Eq. 5). This value can also be inferred using the water balance with precipitation, evapotranspiration and runoff data in a specific basin (Hirschi et al., 2006, Eq. 6). With GLDAS and GRACE products, we applied correlation analysis to find out how much state/flux variables can contribute to TWSC's variance in different basins. After applying a 13-point moving average to remove intra-annual variations in times series, we analyzed annual variations based on the regionally averaged TWS from scaled GRACE and the GLDAS ensemble mean, in combination with annual Chinese water resources bulletins. Annual data from the water resources bulletins were converted from volume (unit: million $\mathrm{m}^{3}$ ) to equivalent water thickness (unit: $\mathrm{cm}$ ), and the multi-year average was removed. To identify a major area with significant TWS increase or depletion in the recent decade, a linear trend of scaled GRACE TWS for each grid was calculated based on linear regression, and the long-term trends of seasonal average TWS were also analyzed. Grids with trends which passed the $F$ test (significant at $95 \%$ confidence level) are marked with black dots in Figs. 7 and 8.

$$
\operatorname{TWSC}_{N}=\mathrm{TWS}_{N}-\mathrm{TWS}_{N-1}
$$

$$
\text { TWSC }=P-E-Q
$$

\section{Results and discussion}

\subsection{Effect of the scaled factor in China}

The effect of the truncation $\left(\right.$ Order $\left._{\max }=60\right)$ and filtering processes ( $300 \mathrm{~km}$ Gaussian filtering) on the GRACE spherical harmonics is equivalent to a low-pass filter; thus the effective resolution of the GRACE TWS product is several hundred kilometers (Tapley et al., 2004). The TWS time series in a $1^{\circ}$ grid was mixed with TWS signals from the surrounding area, leading to leakage errors. When the outside TWS signal was stronger than the inside, the grid value was exaggerated by leakage errors and vice versa. In addition, the sign of gridded TWS could even be changed in cases where inside and outside TWS signals had opposite phases caused by extreme changes in topography, such as in the Turpan basin in northwestern China. As relationships between TWS series at different spatial scales were inferred from land hydrology model simulations, grid-scale factors calculated based on this information could partially correct GRACE TWS and to some extent recover small-scale information (Landerer and Swenson, 2012); thus, these scale factors can be quite helpful for extracting TWS over arbitrary shaped region.

The RMS value of TWS time series in a specific grid is an indicator for the amplitude of local TWS. And the empirical probability density distribution (empirical PDF) curve for RMS values in the research region described the statistical distribution of TWS amplitude within the area. In Fig. 2, empirical PDF curves based on TWS data from modeled TWS data (MOSAIC, VIC, CLM, NOAH, and GLDAS ensemble mean) and observation TWS data (scaled and unscaled GRACE data) were compared. Empirical PDF curves based on scaled GRACE data and modeled data (except CLM) all showed a larger RMS value range on the $x$ axis than that based on unscaled GRACE data. This means the range of TWS amplitude within the research area has been stretched after scaling. In addition, empirical PDF curves based on scaled GRACE data and most modeled data showed that RMS values concentrated in the relatively low numerical zone, with lowest RMS values close to $0 \mathrm{~cm}$. Spatially, areas with low RMS values correspond to northwest China, which is an arid climate zone with vast deserts (Figs. 1, 3b and c). From the comparison in Fig. 3, we can also see that scaled GRACE TWS has a similar distribution of amplitude to that from the GLDAS ensemble mean over China, particularly the boundary with RMS of $3 \mathrm{~cm}$, separating arid and humid climate zones. TWS is quite stable over some part of the oceans and major deserts around the world; thus a small RMS for TWS in these areas indicates small data noise in GRACE TWS (Sakumura et al., 2014). Both the empirical PDFs and the spatial distribution of the RMS of the TWS suggested that grid-scale factors could correct the amplitude of TWS in space. Previous research has demonstrated that correction for leakage is critical to regional TWS analysis (Chen et al., 2014).

Regionally averaged TWS time series from scaled and unscaled GRACE data are highly correlated, and this means that the fluctuation process in TWS has not been heavily influenced by the scale factors. At the same time, the values of TWS were all amplified to different degrees (Table 5), with the amplitudes in the Huai River basin and Zhujiang basin increasing over $50 \%$. However, in the Liao River basin and Yellow River basin, only small changes occurred $(<10 \%)$. The slopes in Table 5 can be regarded as the basin-specific scale factors for GRACE TWS. Generally, basins with large area are less affected by leakage errors and have slopes close to 1 . 


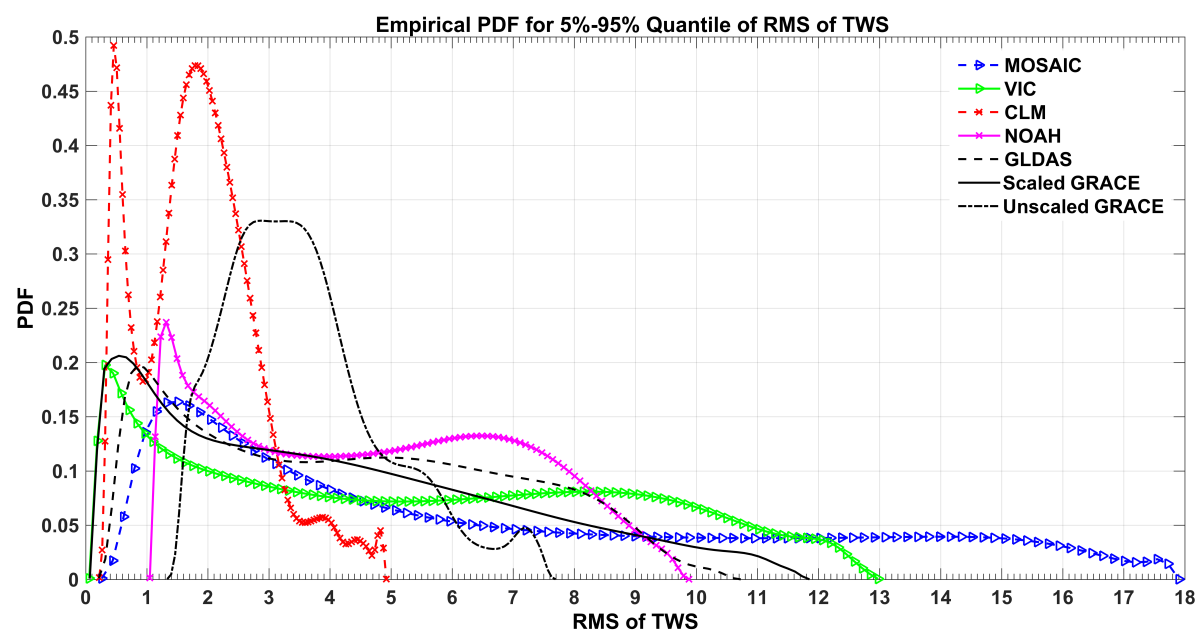

Figure 2. Empirical probability density distributions of root-mean-square of TWS from the scaled GRACE data, the unscaled GRACE data, and model simulations (only TWS values between the 5th and 95th quantiles are considered); unit of RMS is centimeters.
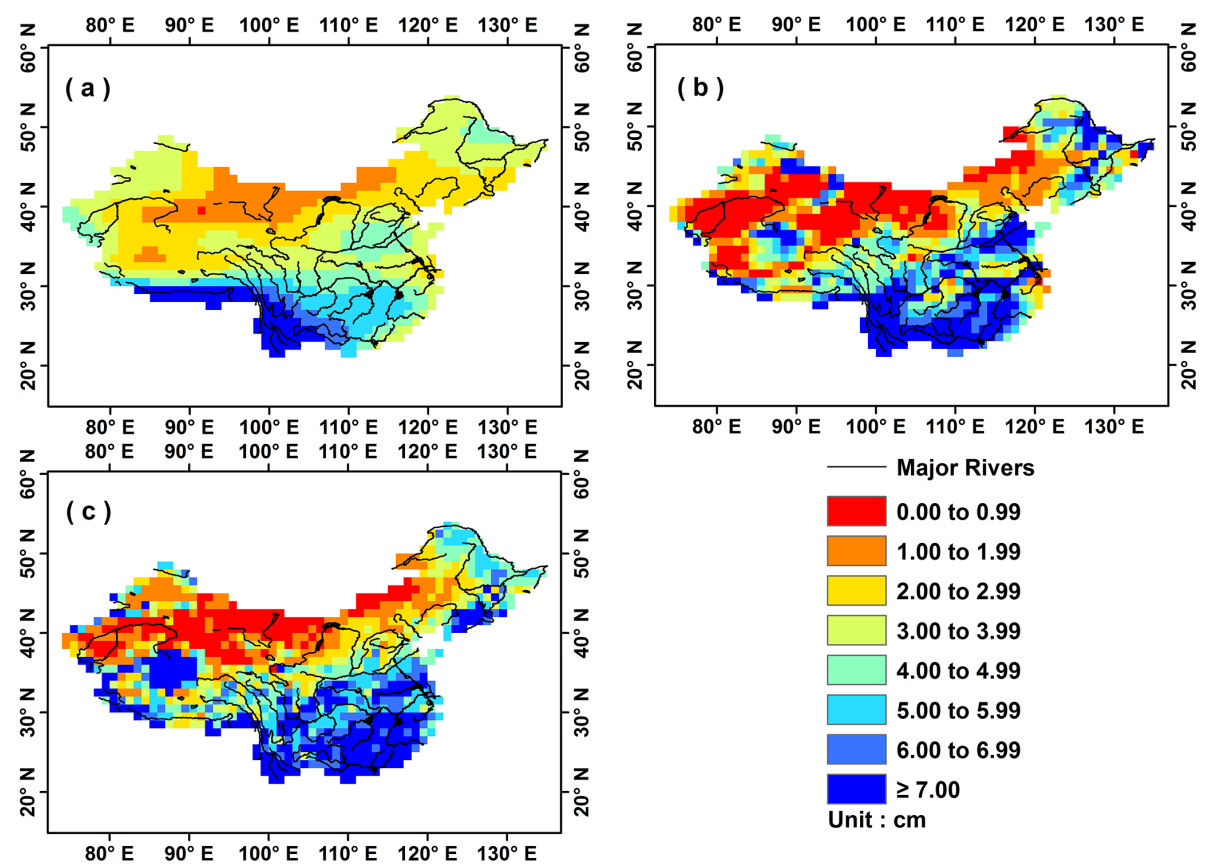

Figure 3. (a) Root-mean-square of TWS from the unscaled GRACE data, (b) the scaled GRACE data, and (c) the GLDAS ensemble mean.

Table 5. Slopes of linear least squares fittings for basin-averaged TWS from the scaled and the unscaled GRACE data calculated in Eq. (4).

\begin{tabular}{llllllllll}
\hline Region & HLJ & LR & HaiR & HuaiR & YR & CJ & ZJ & SERs & CHN \\
\hline Factor & 1.26 & 1.10 & 1.32 & 1.57 & 1.08 & 1.34 & 1.54 & 1.11 & 1.19 \\
$R^{2}$ & 0.996 & 0.989 & 0.988 & 0.994 & 0.982 & 0.992 & 0.996 & 0.991 & 0.982 \\
\hline
\end{tabular}

\subsection{Annual variations in regional TWS time series}

In general, fluctuations in annual precipitation could appropriately characterize the interannual variability in regionally averaged TWS, but distinct processes also exist in certain basins or over certain periods because of the influence of other factors (Figs. 4, 6). TWS in China was at a relatively high level before 2006, but then stayed at a continuously low level with a high variability from 2006 to 2012. During this 

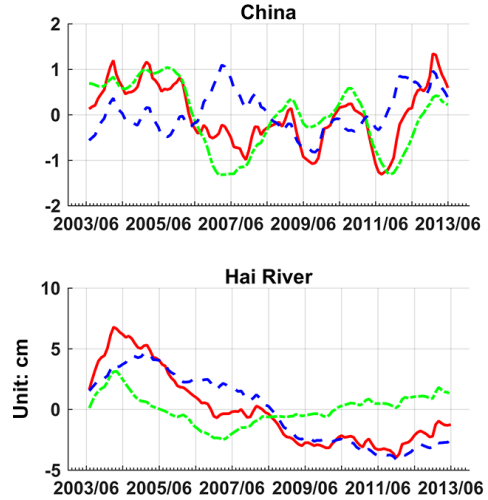

Changjiang

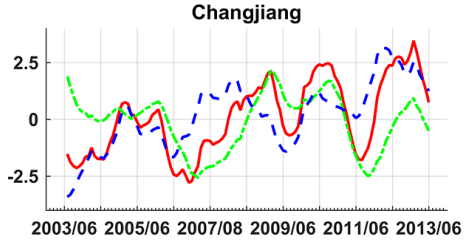

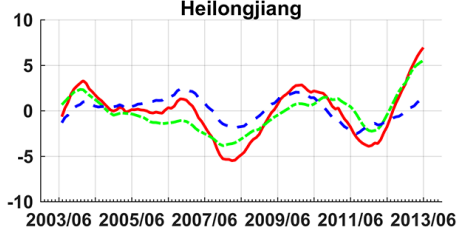
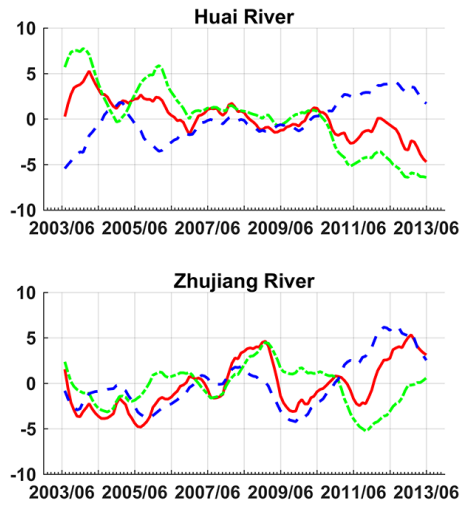
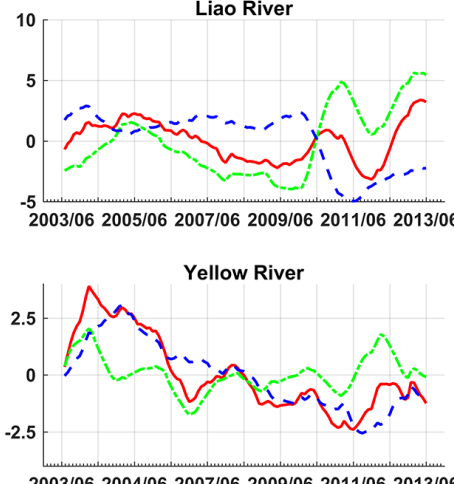

$2003 / 062004 / 062007 / 062009 / 062011 / 062013 / 06$

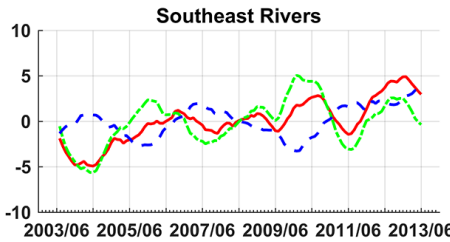

- 13-PMA TWS-GRACE ---- 13-PMA TWS-GLDAS - - - 13-PMA Residual

Figure 4. Regionally averaged monthly TWS series (2003-2013) from the scaled GRACE data and the GLDAS ensemble mean, and their residual time series for China and eight of its basins (all time series have been processed with 13-point moving average; unit: $\mathrm{cm}$ ).
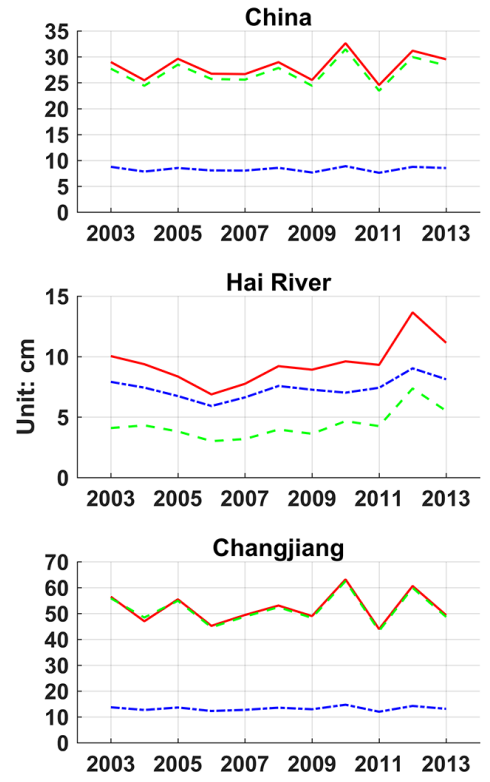
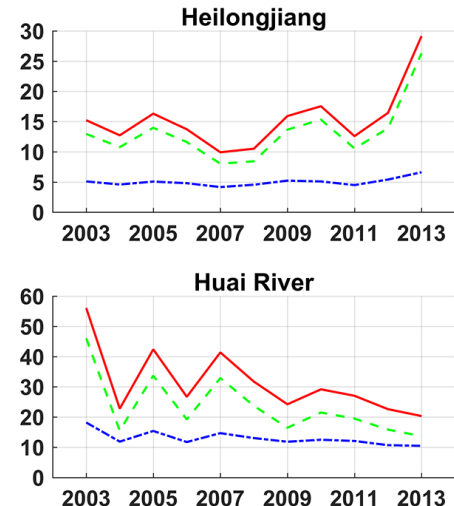

Zhujiang River

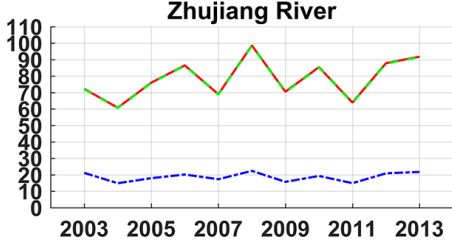

Liao River
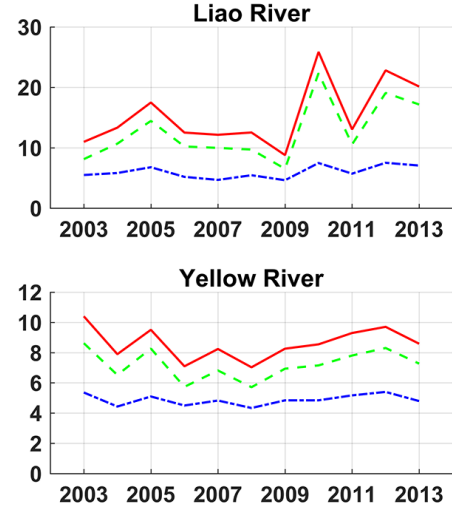

Southeast Rivers

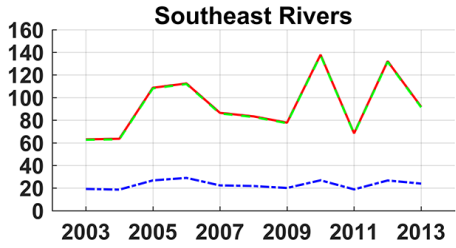

Gross of water resource - - Surface water resource -----Groundwater resource

Figure 5. Annual variations of water resources in China as a whole and eight of its basins from 2003 to 2013 (unit: cm).

period, severe droughts occurred frequently and caused particularly sharp declines in TWS in 2007, 2009, and 2011. TWS in China did not recover to the same level as in 2005 until 2013. This periodic process was partially reflected in the TWS estimates from the GLDAS ensemble mean (mostly soil moisture storage) but not in the residual series or water resources records (Figs. 4, 5).
In northeast China, TWS observations and simulation estimates in the Heilongjiang River basin were consistent and showed no long-term trend; the region mainly suffered from two severe regional droughts in 2007 and 2011 and a significant basin flood event in 2013. Annual precipitation in the Liao River basin continuously declined from 2005 to 2009 and then increased rapidly in following years; TWS estimates 

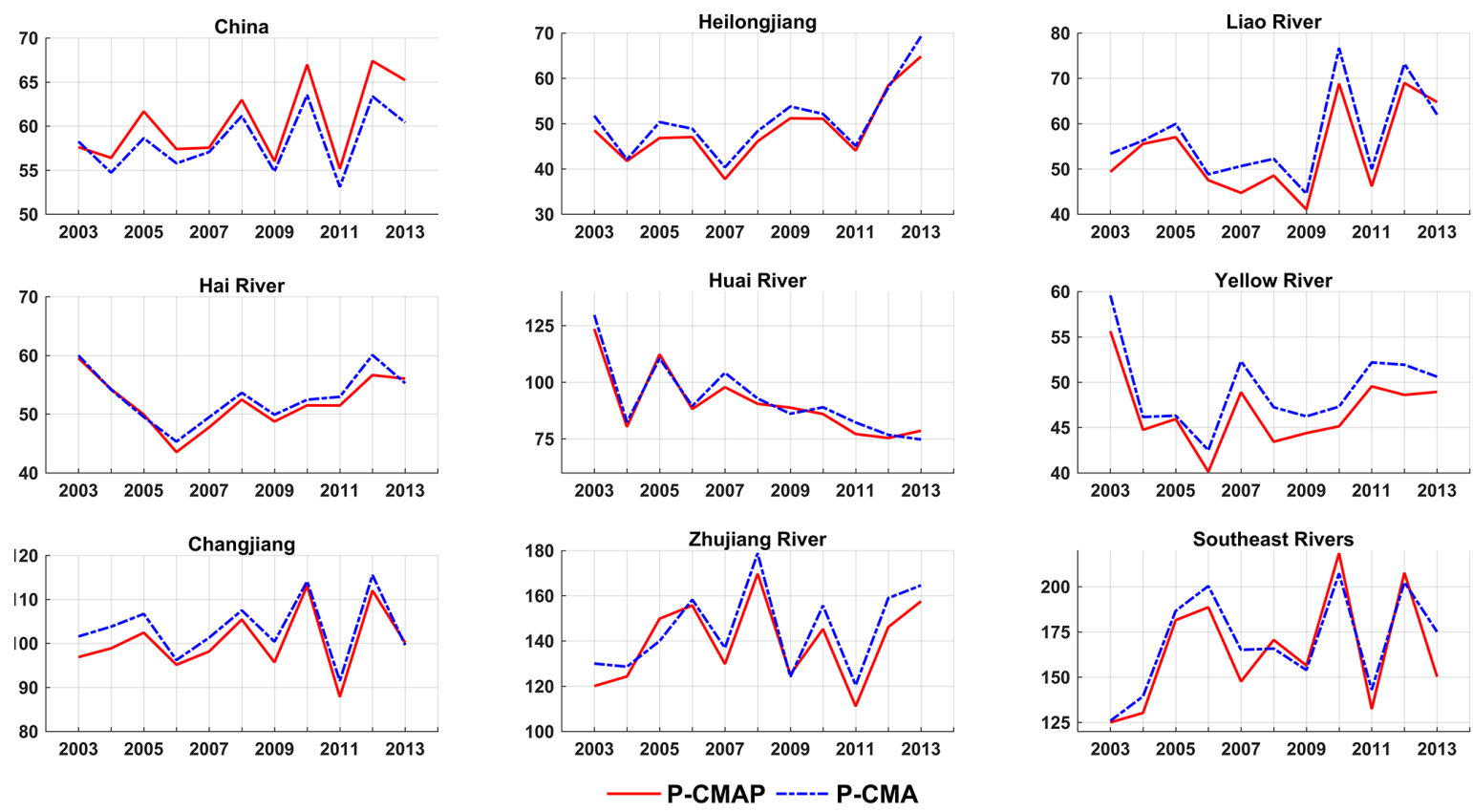

Figure 6. Regionally averaged annual precipitation for China and eight of its basins from 2003 to 2013 (unit: $\mathrm{cm}$ ). $P$ from CMAP refers to precipitation grid data from GLDAS forcing, and $P$ from CMA refers to precipitation grid data based on station observations provided by China Meteorological Administration.

and water resources records both captured this process precisely. Nevertheless, it seemed that the TWS observations failed to respond to heavy precipitation in 2010 , with a $9 \mathrm{~cm}$ increase in TWS estimates and only a $3 \mathrm{~cm}$ increase in TWS observations.

In north China, annual precipitation in Hai River basin changed following a V-shaped process, with year 2006 as the turning point, which can also be recognized from the TWS estimates and water resources records. After a rapid decline from 2004 to $2006\left(-2.48 \mathrm{~cm} \mathrm{yr}^{-1}\right)$, the TWS from the scaled GRACE data in Hai River basin became stable around 2007. Contrary to increasing precipitation, TWS dropped $3 \mathrm{~cm}$ in 2008 and continued to decline slowly at a rate of $-0.22 \mathrm{~cm} \mathrm{yr}^{-1}$ until it started to recover in 2012. The TWS in Hai River basin generally showed a linear decreasing trend $\left(-1.27 \mathrm{~cm} \mathrm{yr}^{-1}\right)$ during 2004-2011. The residual between TWS from scaled GRACE data and the GLDAS ensemble mean could be treated approximately as the sum of surface reservoir and groundwater storage. Moreover, detection depth of GRACE is much deeper than the layers considered in models $(1.90 \mathrm{~m}$ in VIC, $2.00 \mathrm{~m}$ in NOAH, $3.50 \mathrm{~m}$ in Mosaic, and $3.43 \mathrm{~m}$ in CLM) and in field monitoring (shallow aquifer). Although the increasing precipitation seemed to have alleviated the depletion trend in these areas, we should not ignore the large gap $\left(-1.80 \mathrm{~cm} \mathrm{yr}^{-1}\right)$ between the trends of the time series of the residuals and summed water resources records $\left(-1.28\right.$ and $\left.0.50 \mathrm{~cm} \mathrm{yr}^{-1}\right)$ during 2006-2011. The gap between these time series probably suggests that the long-term effect of over-exploitation of groundwater still remained, even though water-saving management practices had already been carried out in this basin, and water storage would suffer even worse depletion in the future drought years. Similar to the Hai River basin, the TWS from scaled GRACE data in the Yellow River basin followed a nearly linear decreasing trend $\left(-0.73 \mathrm{~cm} \mathrm{yr}^{-1}\right)$ during 2004-2011, and it changed more slowly $\left(0.13 \mathrm{~cm} \mathrm{yr}^{-1}\right)$ after 2007. The basin-averaged TWS, gross water resource, and precipitation also showed different processes in the latter half of research period. However, Fig. 7 reveals that the area with large long-term decreasing trends is mainly located midstream of the Yellow River basin (Shanxi and Shaanxi provinces), which is famous for coal mining. To identify the exact causes for decreasing TWS, more local statistical data and groundwater level records should be collected. Over recent decades, the TWS in the Huai River basin has shown a long-term descending trend $\left(-0.56 \mathrm{~cm} \mathrm{yr}^{-1}\right)$, which is similar to annual precipitation over this basin. The TWS from GLDAS ensemble mean also showed good agreement.

Annual variations in TWS from scaled GRACE data, the GLDAS ensemble mean, and water resources records are more similar across basins in south China than they are in north China. The TWS in the Changjiang River basin, Zhujiang basin, and southeast rivers basin all followed an increasing trend from 2003 to 2013, at $0.35,0.55$, and $0.70 \mathrm{~cm} \mathrm{yr}^{-1}$, respectively. As a result of typhoons and tropical storms, the TWS in these basins also had much stronger fluctuations than in north China. 

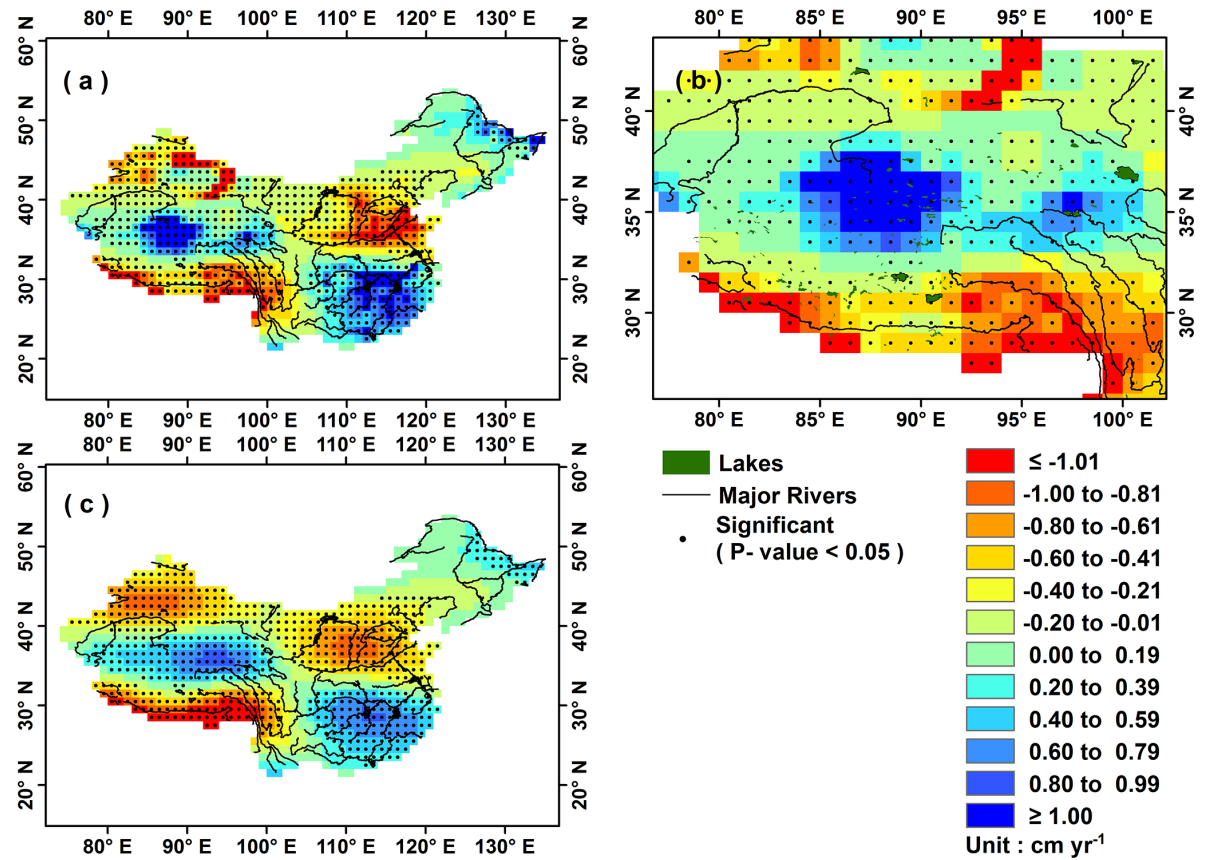

Figure 7. Spatial distribution of trends derived from linear least squares regression for TWS in 2003-2013 (unit: $\mathrm{cm} \mathrm{yr}^{-1}$ ); (a) and (b) are linear trends from the scaled GRACE data and a detailed diagram of the data for west part of China, (c) is the linear trend from the unscaled GRACE data. Grids with trends significant ( $F$ test) at $95 \%$ confidence level are marked with black dots.

The TWS variations observed by GRACE are integrated information from different components in the vertical profile. Compared to water storage in surface soil layers, snow cover and canopy water storage are almost negligible in most regions, and analysis results in China suggested that changes in soil moisture contributed significantly to TWSC (Table 6). The percentage of TWSC variance explained by SMC could be as high as $62 \%$ at the national scale. In most basins, over half of the TWSC variance could be attributed to SMC, with high percentages in the Changjiang River basin and Zhujiang basin (64 and 67\%). In the Heilongjiang River basin, SMC played a less important role in TWSC (38\%). Fluctuations in hydrologic fluxes over the basin jointly affected water storage. According to correlation analysis based on GRACE TWS and GLDAS fluxes, precipitation, evapotranspiration, and runoff each contributed 46,41 , and $32 \%$, respectively, to the TWSC variance in China (Table 6). As most basins we focused on are under control of the monsoon climate, precipitation and runoff generally showed higher contributions to the TWSC variance than evapotranspiration did. Overall, precipitation was found to have a much higher impact on TWSC in the south than in the north, with the highest explained variance in the Zhujiang basin $(60 \%)$, followed by that in the Changjiang River basin $(44 \%)$.

\subsection{Spatial pattern of linear trend analysis}

When focusing on differences between large regions, spatial patterns of linear trends calculated from scaled and unscaled
Table 6. Coefficient of determination $R^{2}$, based on Pearson correlation, between precipitation $(P)$, evapotranspiration $(E)$, runoff $(Q)$, soil moisture change (SMC) from GLDAS ensemble mean, and TWSC from the scaled GRACE data in 2003-2013.

\begin{tabular}{llllllllll}
\hline & HLJ & LR & HaiR & HuaiR & YR & CJ & ZJ & SERs & CHN \\
\hline$P$ & 0.04 & 0.20 & 0.18 & 0.35 & 0.41 & 0.44 & 0.60 & 0.23 & 0.46 \\
$E$ & 0.00 & 0.08 & 0.10 & 0.09 & 0.28 & 0.25 & 0.30 & 0.00 & 0.32 \\
$Q$ & 0.08 & 0.26 & 0.291 & 0.31 & 0.38 & 0.47 & 0.50 & 0.18 & 0.41 \\
SMC & 0.38 & 0.52 & 0.527 & 0.57 & 0.46 & 0.64 & 0.67 & 0.51 & 0.67 \\
\hline
\end{tabular}

GRACE TWS are consistent (Fig. 7a, c). But at a local scale, results from scaled GRACE TWS better correspond to natural features of the TWS intensity distribution. Areas around river networks usually have a high level of TWS, thus presenting large absolute values of trends. From 2003 to 2013, four main regions were identified with intensive and significant long-term trends in TWS. Results also revealed that seasons in a year made different contributions to these trends (Fig. 8).

According to the analysis in the previous section, we inferred that human activities rather than climate parameters could be responsible for the significant TWS depletion in north China, as withdrawals usually surpass net recharge in arid and semiarid regions. Severe areas are mainly located in the province of Shanxi and the southern part of the Hebei province, with decreasing trends less than $-0.80 \mathrm{~cm} \mathrm{yr}^{-1}$. And offset to loss rate caused by mass gains from reser- 

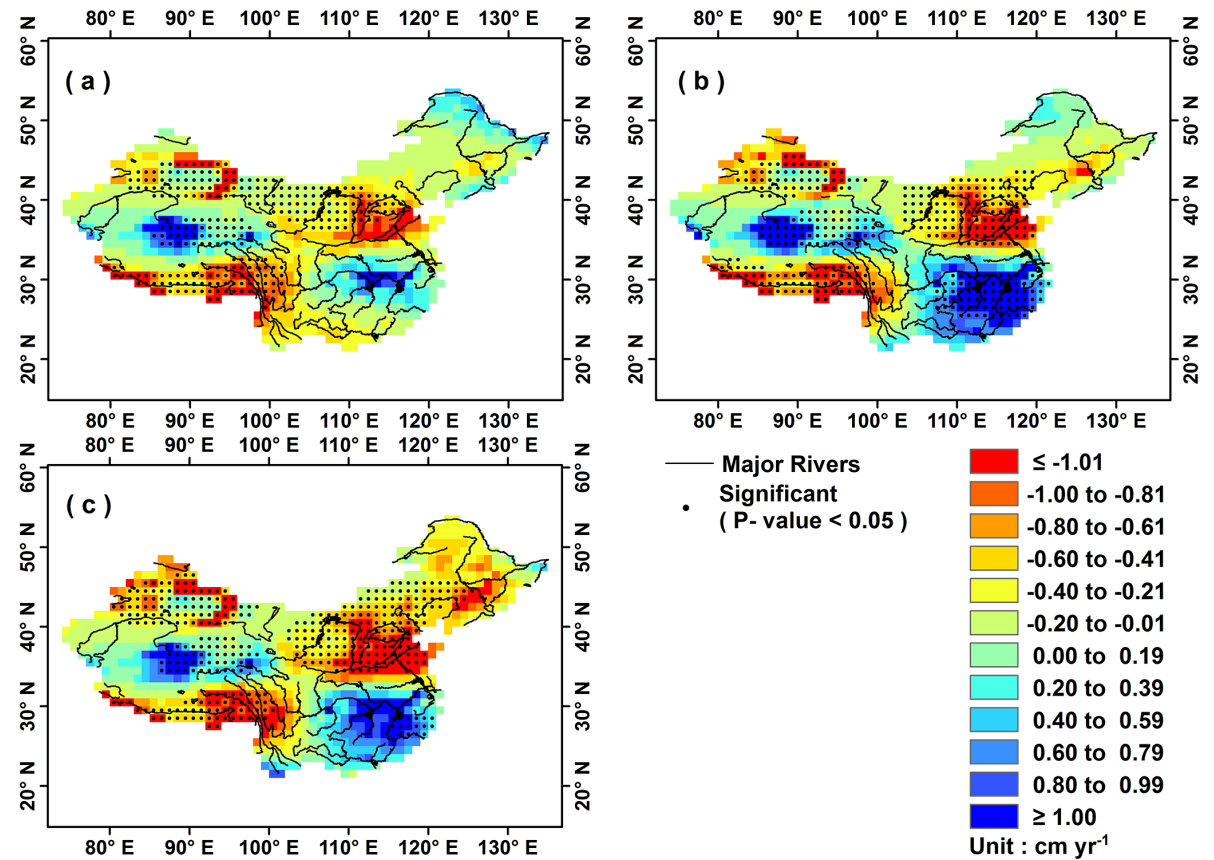

Figure 8. Spatial distribution of trends derived from linear least squares regression for seasonally averaged TWS in 2003-2013 from the scaled GRACE data (unit: $\mathrm{cm} \mathrm{yr}^{-1}$ ); (a) spring (March-May); (b) summer (June-August); (c) autumn (September-November). Grids with trends significant ( $F$ test) at $95 \%$ confidence level are marked by black dots.

voir regulation, water diversion and coal transport in this region was estimated to $0.76 \mathrm{~cm} \mathrm{yr}^{-1}$ (Tang et al., 2013). In the Shanxi province, the east to mid-section of Yellow River, coal mining not only has disturbed normal recharge to the nearby aquifer but has also caused over-exploitation of groundwater. The groundwater is a major source of water consumption in the Huang-Huai-Hai Plain; agricultural irrigation consumes large amounts of freshwater pumped from deep wells every year (Foster et al., 2004; Kendy et al., 2004). This poor condition deteriorates with seasons and the depletion becomes most severe, impacting the largest area in autumn. Considering irrigation demand concentrated mostly in MMA and high social water consumption comes with JJA, TWS probably needs time to show all this influence in SON. The southwest rivers region (Yarlung Zangbo River, Nu River, and Lancang River) also showed significant TWS depletion, particularly in the upstream and downstream portions of the Yarlung Zangbo River. The area impacted by significant depletion was the largest in spring, while the depletion also became the most severe in autumn. Climate observation across this region proved that annual precipitation was decreasing over 11 years, with significant droughts in 2006, 2009, and 2012. Moreover, previous research also found ice loss in Himalaya from 2003 to 2007 (Matsuo and Heki, 2010).

Along with increasing precipitation in southeast China, there were significant increasing trends in TWS over the middle and lower reaches of the Changjiang River and south- eastern coastal area. The main contribution to this significant increase occurred during the summer, when precipitation was the most concentrated of the year. There are two places that showed significant TWS increases in the Tibetan Plateau. One of these areas is around the Hoh Xil Mountains and the other is the headstream region of the Yellow River; they have maximum increasing trends of 2.59 and $1.77 \mathrm{~cm} \mathrm{yr}^{-1}$, respectively. The Hoh Xil Mountains are located at the intersection of the inland lakes in the Qangtang Plateau and the north source of the Changjiang River. The headstream region of the Yellow River lies at the plateau's two largest freshwater lakes, Eling Lake and Zaling Lake. Previous research applied multi-source satellite data to reconstruct volume changes in the Tibetan Plateau's major lakes, and found that they showed similar spatial distribution to mass variations in GRACE during 2003-2010 (Song et al., 2013). According to satellite images, lakes in Hoh Xil overall showed a trend of expansion during 2000-2011. Further analysis suggested that increasing precipitation and decreasing evaporation were major factors contributing to this trend, and additional water recharge from melting glacier and frozen soil caused by climate warming was a minor factor (Yao et al., 2014; Duan et al., 2007). In the headstream region of the Yellow River, precipitation is the main recharge source to runoff, with a ratio of $63 \%$. Local observations revealed that there was an increasing trend in runoff as this region was becoming warmer and wetter during the period 2000 2012 (Lan et al., 2010, 2013; Wang et al., 2014). The Chi- 
nese government has launched an ecological protection and construction project in the Three-River Source region that started in 2005. According to monitoring data from the Qinghai Provincial Meteorological Bureau, average lake extents during 2005-2012 showed an increase of 34.7 and $64.4 \mathrm{~km}^{2}$, compared to those during 2003-2004 for Eling Lake and Zaling Lake, respectively.

In addition to the above large areas, there are also some other small regions showing strong TWS changes from 2003 to 2013. Along the northeast country border, there is significant TWS increase $\left(0.34 \sim 1.19 \mathrm{~cm} \mathrm{yr}^{-1}\right)$; this is mostly contributed by winter. The central part of the province of Jilin in northeast China shows severe TWS depletion in autumn $\left(-1.10 \sim-2.28 \mathrm{~cm} \mathrm{yr}^{-1}\right)$, but these linear trends have not passed the significance test $(P$ value $<0.05)$. In northwest China, the unscaled GRACE data only show significant water depletion mainly around Tianshan Mountains, which is also identified with ice loss in previous research (Matsuo and Heki, 2010). However, trends from the scaled GRACE TWS also illustrate a significant TWS increase in the Turpan basin, while there is a depletion in its surrounding mountains. The Turban basin is the lowest basin in China, and Fig. 3b shows that the basin has a much smaller TWS amplitude than that in surrounding mountains. An extreme arid climate and local topography features in this region could make TWS more sensitive to climate change. Complex terrain in this region leads to a more complicated GRACE TWS signal mixture at a large spatial scale. Even though scale factors might have separated mixed TWS signals, limitations in factors' production should also be taken care of (Launderer and Swenson, 2012).

\section{Summary and conclusions}

In this study we analyzed annual variations in TWS over 11 years in China as a whole and eight of its basins, based on scaled GRACE data in combination with GLDAS simulations and water resources records. Areas with significant long-term trends were also identified and discussed. The major points are summarized as follows.

1. Grid-scale factors could adequately correct leakage errors in the GRACE products, and the scaled data gained more spatial details of the TWS intensity distribution. The values of the regionally averaged TWS were amplified after scale factors were applied. These increased percentages reached up to over $50 \%$ in the Huai River basin $(57 \%)$ and Zhujiang basin $(54 \%)$, but were tiny for basins with larger sizes, such as the Liao River basin $(10 \%)$ and Yellow River basin $(8 \%)$.

2. The TWS at the national scale stayed at a relatively low level. These values exhibited high-intensity variations from 2006 to 2012, before recovering to their 2003-2005 condition. The TWS in the Hai River basin,
Huai River basin, and Yellow River basin almost decreased linearly, while it increased in fluctuations in the Changjiang River basin, Zhujiang basin, and southeast rivers basin. The TWS variations generally followed the variations in annual precipitation at the basin scale, but they showed inverse changes in 2007-2013 in both the Hai River basin and Yellow River basin.

3. Changes in soil moisture storage contributed $62 \%$ of the TWSC variance at the national scale, and the percentages were generally beyond $50 \%$ in all basins with exceptions in the Heilongjiang River basin (38\%) and Yellow River basin $(46 \%)$. Under the control of the monsoon climate, precipitation and runoff explained more variance in TWSC than evapotranspiration did, and the precipitation's ability to explain TWSC variations was stronger in the south basins than in the north, reaching up to $60 \%$ in the Zhujiang basin.

4. From 2003 to 2013, the southwest rivers region and north China showed significant water storage depletions, and the area of depletion was largest in spring and summer, respectively. The middle and lower reaches of the Changjiang River and southeastern coastal area, as well as the Hoh Xil Mountains, and the headstream region of the Yellow River in the Tibetan Plateau, all exhibited significant increases in TWS. These identified trends reflected TWS's responses to regional climate changes and human activities.

The current data period of GRACE products is shorter than some existing remote sensing data sets or site records, and the resolution and accuracy of GRACE data also need to be improved. However, TWS from GRACE has proved to be valuable in understanding large-scale hydrological processes over land. The results in this study would be helpful for water resources management and climate change impact research. More sources of data will be added to further analyze regions or phenomena addressed in this study. The GRACE FollowOn mission has already been scheduled, and will continue to support monitoring and research on TWS in the future.

Acknowledgements. This research received financial support from the International Science \& Technology Cooperation Program of China (grant number: 2013DFG21010). The GLDAS simulations were provided by Goddard Earth Sciences (GES) Data and Information Services Center (DISC) (http: //disc.sci.gsfc.nasa.gov/services/disc/services/grads-gds/gldas). GRACE land data (available at http://grace.jpl.nasa.gov) processing algorithms were provided by Sean Swenson, and supported by the NASA MEaSUREs Program; the authors would also like to thank the anonymous reviewers for the valuable comments that helped to improve the manuscript.

Edited by: B. D. Malamud

Reviewed by: two anonymous referees 


\section{References}

Andersen, O. B., Seneviratne, S. I., Hinderer, J., and Viterbo, P.: GRACE-derived terrestrial water storage depletion associated with the 2003 European heat wave, Geophys. Res. Lett., 32, L18405, doi:10.1029/2005GL023574, 2005.

Betts, A. K., Chen, F., Mitchell, K., and Janjic, Z. I.: Assessment of the land surface and boundary layer models in two operational versions of the NCEP Eta model using FIFE data, Mon. Weather Rev., 125, 2896-2916, 1997.

Bonan, G. B., Oleson, K. W., Vertenstein, M., Levis, S., Zeng, X. B., Dai, Y. J., Dickinson, R. E., and Yang, Z. L.: The land surface climatology of the NCAR Land Surface Model coupled to the NCAR Community Climate Model, J. Climate, 11, 1307-1326, 1998.

Chen, F., Mitchell, K., Schaake, J., Xue, Y. K., Pan, H. L., Koren, V., Duan, Q. Y., Ek, M., and Betts, A.: Modeling of land-surface evaporation by four schemes and comparison with FIFE observations, J. Geophys. Res., 101, 7251-7268, 1996.

Chen, J. L., Wilson, C. R., Famiglietti, J. S., and Rodell, M.: Attenuation effect on seasonal basin-scale water storage changes from GRACE time-variable gravity, J. Geodesy., 81, 237-245, 2007.

Chen, J. L., Wilson, C. R., Tapley, B. D., Yang, Z. L., and Niu, G. Y.: The 2005 drought event in the Amazon River basin as measured by GRACE and estimated by climate models, J. Geophys. Res., 114, B05404, doi:10.1029/2008JB006056, 2009.

Chen, J. L., Wilson, C. R., and Tapley, B. D.: The 2009 exceptional Amazon flood and interannual terrestrial water storage change observed by GRACE, Water Resour. Res, 46, W12526, doi:10.1029/2010WR009383, 2010.

Chen, J. L., Li, J., Zhang, Z. Z., and Ni, S. N.: Long-term groundwater variations in Northwest India from satellite gravity measurements, Global Planet. Change, 116, 130-138, 2014.

Crowley, J. W., Mitrovica, J. X., Bailey, R. C., Tamisiea, M. E., and Davis, J. L.: Annual variations in water storage and precipitation in the Amazon Basin, J. Geodesy., 82, 9-13, 2008.

Dai, Y. J. and Zeng, Q. C.: A land surface model (IAP94) for climate studies, Part I: Formulation and validation in off-line experiments, Adv. Atmos. Sci., 14, 443-460, 1997.

Dickinson, R. E., Henderson-Sellers, A., and Kennedy, P. J.: Biosphere-atmosphere Transfer Scheme (BATS) Version $1 \mathrm{e}$ as Coupled to the NCAR Community Climate Model, NCAR Technical Note NCAR/TN-387+STR, NCAR, doi:10.5065/D67W6959, 1993.

Duan, J. B., Zhong, M., Yan, W. M., and Jiang, M.: Recovery of land water storage variations in Chinese mainland by use of grace data, J. Geodesy., 27, 68-71, 2007 (in Chinese).

Ek, M. B., Mitchell, K. E., Lin, Y., Rogers, E., Grunmann, P., Koren, V., Gayno, G., and Tarpley, J. D.: Implementation of Noah land surface model advances in the National Centers for Environmental Prediction operational mesoscale Eta model, J. Geophys. Res., 108, 8851, doi:10.1029/2002JD003296, 2003.

Famiglietti, J. S.: Remote sensing of terrestrial water storage, soil moisture and surface waters, in: The State of the Planet: Frontiers and Challenges in Geophysics, edited by: Sparks, R. S. J. and Hawkesworth, C. J., American Geophysical Union, Washington, D.C., 197-207, 2004.
Famiglietti, J. S., Lo, M., Ho, S. L., Bethune, J., Anderson, K. J., Syed, T. H., Swenson, S. C., de Linage, C. R., and Rodell, M.: Satellites measure recent rates of groundwater depletion in California's Central Valley, Geophys. Res. Lett., 38, L03403, doi:10.1029/2010GL046442, 2011.

Feng, W., Zhong, M., Lemoine, J. M., Biancale, R., Hsu, H. T., and Xia, J.: Evaluation of groundwater depletion in North China using the Gravity Recovery and Climate Experiment (GRACE) data and ground-based measurements, Water Resour. Res., 49, 2110-2118, 2013.

Foster, S., Garduno, H., Evans, R., Olson, D., Tian, Y., Zhang, W. Z., and Han, Z. S.: Quaternary aquifer of the North China Plain assessing and achieving groundwater resource sustainability, Hydrogeol. J., 12, 81-93, 2004.

Hirschi, M., Seneviratne, S. I., and Schar, C.: Seasonal variations in terrestrial water storage for major mid-latitude river basins, J. Hydrometeorol., 7, 39-60, 2006.

Hu, X. G., Chen, J. L., Zhou, Y. H., Cheng, H., and Liao, X. H.: Seasonal water storage change of the Yangtze River Basin detected by GRACE, Sci. China Ser. D, 49, 483-491, 2006.

Jin, S. G. and Feng, G. P.: Large-scale variations of global groundwater from satellite gravimetry and hydrological models, 2002 2012, Global Planet. Change, 106, 20-30, 2013.

Kendy, E., Zhang, Y. Q., Liu, C. M., Wang, J. X., and Steenhuis, T.: Groundwater recharge from irrigated cropland in the North China Plain: case study of Luancheng County, Hebei Province, 1949-2000, Hydrol. Process., 18, 2289-2302, 2004.

Kim, H., Pat Yeh, J. F., Oki, T., and Kanae, S.: Role of rivers in the seasonal variations of terrestrial water storage over global basins, Geophys. Res. Lett., 36, L17402, doi:10.1029/2009GL039006, 2009.

Koren, V., Schaake, J., Mitchell, K., Duan, Q. Y., Chen, F., and Baker, J. M.: A parameterization of snowpack and frozen ground intended for NCEP weather and climate models, J. Geophys. Res., 104, 19569-19585, 1999.

Koster, R. D. and Suarez, M. J.: Energy and Water Balance Calculations in the Mosaic LSM, NASA Technical Memorandum 104606, NASA, 9, 76 pp., 1996.

Lan, Y. C., Zhao, G. H., Zhang, Y. N., Wen, J., Liu, J. Q., and Hu, X. L.: Response of runoff in the source of the Yellow River to climate warming, Quatern. Int., 226, 60-65, 2010.

Lan, Y. C., Lu, C. Y., La, C. F., and Sheng, Y. P.: The factor of climate shift to warm-humid in the source regions of the Yellow River and its hydrologic response, J. Glaciol. Geocryl., 35, 920928, 2013 (in Chinese).

Landerer, F. W. and Swenson, S. C.: Accuracy of scaled GRACE terrestrial water storage estimates, Water Resour. Res., 48, W04531, doi:10.1029/2011WR011453, 2012.

Landerer, F. W., Dickey, J. O., and Gntner, A.: Terrestrial water budget of the Eurasian pan-Arctic from GRACE satellite measurements during 2003-2009, J. Geophys. Res., 115, D23115, doi:10.1029/2010JD014584, 2010.

Leblanc, M. J., Tregoning, P., Ramillien, G., Tweed, S. O., and Fakes, A.: Basin-scale, integrated observations of the early $21 \mathrm{st}$ century multiyear drought in southeast Australia, Water Resour. Res., 45, W04408, doi:10.1029/2008WR007333, 2009.

Lettenmaier, D. P. and Famiglietti, J. S.: Water from on high, Nature, 444, 562-563, 2006. 
Liang, X., Lettenmaier, D. P., Wood, E. F., and Burges, S. J.: A simple hydrologically based model of land surface water and energy fluxes for GSMs, J. Geophys. Res., 99, 14415-14428, 1994.

Liang, X., Lettenmaier, D. P., and Wood, E. F.: One-dimensional statistical dynamic representation of subgrid spatial variability of precipitation in the two-layer variable infiltration capacity model, J. Geophys. Res., 101, 21403-21422, 1996.

Long, D., Scanlon, B. R., Longuevergne, L., Sun, A. Y., Fernando, D. N., and Save, H.: GRACE satellites monitor large depletion in water storage in response to the 2011 drought in Texas, Geophys. Res. Lett., 40, 3395-3401, 2013.

Long, D., Longuevergne, L., and Scanlon, B. R.: Global analysis of approaches for deriving total water storage changes from GRACE satellites, Water Resour. Res., 51, 2574-2594, 2015.

Matsuo, K. and Heki, K.: Time-variable ice loss in Asian high mountains from satellite gravimetry, Earth Planet. Sc. Lett., 290, 30-36, 2010.

Moiwo, J. P., Yang, Y., Li, H., Han, S., and Hu, Y.: Comparison of GRACE with in situ hydrological measurement data shows storage depletion in Hai River Basin, northern China, Water SA, 35, 663-670, 2009.

Oleson, K. W., Niu, G. Y., Yang, Z. L., Lawrence, D. M., Thornton, P. E., Lawrence, P. J., Stöckli, R., Dickinson, R. E., Bonan, G. B., Levis, S., Dai, A., and Qian, T.: Improvements to the community land model and their impact on the hydrological cycle, J. Geophys. Res., 113, G01021, doi:10.1029/2007JG000563, 2008.

Phillips, T., Nerem, R. S., Fox-Kemper, B., Famiglietti, J. S., and Rajagopalan, B.: The influence of ENSO on global terrestrial water storage using GRACE, Geophys. Res. Lett., 39, L16705, doi:10.1029/2012GL052495, 2012.

Reager, J. T., Thomas, B. F., Famiglietti, J. S.: River basin flood potential inferred using GRACE gravity observations at several months lead time, Nat. Geosci., 7, 588-592, 2014.

Rodell, M. and Famiglietti, J. S.: Detectability of variations in continental water storage from satellite observations of the time dependent gravity field, Water Resour. Res., 35, 2705-2723, 1999.

Rodell, M. and Famiglietti, J. S.: An analysis of terrestrial water storage variations in Illinois with implications for the Gravity Recovery and Climate Experiment (GRACE), Water Resour. Res., 37, 1327-1339, 2001.

Rodell, M., Houser, P. R., Jambor, U., Gottschalck, J., Mitchell, K., Meng, C. J., Arsenault, K., Cosgrove, B., Radakovich, J., Bosilovich, M., Entin, J. K., Walker, J. P., Lohmann, D., and Toll, D.: The Global Land Data Assimilation System, B. Am. Meteorol. Soc., 85, 381-394, 2004.

Rodell, M., Velicogna, I., and Famiglietti, J. S.: Satellite-based estimates of groundwater depletion in India, Nature, 460, 999-1002, 2009.

Sakumura, C., Bettadpur, S., and Bruinsma, S.: Ensemble prediction and intercomparison analysis of GRACE time-variable gravity field models, Geophys. Res. Lett., 41, 1389-1397, 2014.

Schmidt, R., Schwintzed, P., Flechtner, F., Reigbera, C., Güntnera, A., Döllb, P., Ramillienc, G., Cazenavec, A., Petrovica, S., Jochmanna, H., and Wünsch, J.: GRACE observations of changes in continental water storage, Global Planet. Change, 50, 112-126, 2006.

Song, C. Q., Huang, B., and Ke, L. H.: Modeling and analysis of lake water storage changes on the Tibetan Plateau using multimission satellite data, Remote Sens. Environ., 135, 25-35, 2013.
Strassberg, G., Scanlon, B. R., and Rodell, M.: Comparison of seasonal terrestrial water storage variations from GRACE with groundwater-level measurements from the High Plains Aquifer (USA), Geophys. Res. Lett., 34, L14402, doi:10.1029/2007GL030139, 2007.

Su, X. L., Ping, J. S., and Ye, Q. X.: Terrestrial water variations in the North China Plain revealed by the GRACE mission, Sci. China Earth Sci., 54, 1965-1970, 2011.

Swenson, S. C. and Wahr, J.: Monitoring changes in continental water storage with GRACE, Space Sci. Rev., 108, 345-354, 2003.

Swenson, S. C. and Wahr, J.: Post-processing removal of correlated errors in GRACE data, Geophys. Res. Lett., 33, L08402, doi:10.1029/2005GL025285, 2006.

Syed, T. H., Lakshmi, V., Paleologos, E., Lohmann, D., Mitchell, K., and Famiglietti, J. S.: Analysis of process controls in land surface hydrological cycle over the continental United States, J. Geophys. Res., 109, 1-11, 2004.

Syed, T. H., Famiglietti, J. S., Chen, J. L., Rodell, M., Seneviratne, S. I., Viterbo, P., and Wilson, C. R.: Total basin discharge for the Amazon and Mississippi river basins from GRACE and a landatmosphere water balance, Geophys. Res. Lett., 32, L24404, doi:10.1029/2005GL024851, 2005.

Syed, T. H., Famiglietti, J. S., Rodell, M., Chen, J. L., and Wilson, C. R.: Analysis of terrestrial water storage changes from GRACE and GLDAS, Water Resour. Res., 44, W02433, doi:10.1029/2006WR005779, 2008.

Tang, J. S., Cheng, H. W., and Liu, L.: Assessing the recent droughts in Southwestern China using satellite gravimetry, Water Resour. Res., 50, 3030-3038, 2014.

Tang, Q. H., Zhang, X. J., and Tang, Y.: Anthropogenic impacts on mass change in North China, Geophys. Res. Lett., 40, 3924 3928, 2013.

Tapley, B., Bettadpur, S., Ries, J., Thompson, P., and Watkins, M.: GRACE measurements of mass variability in the Earth system, Science, 305, 503-505, 2004.

Wahr, J., Swenson, S. C., Zlotnicki, V., and Velicogna, I.: Timevariable gravity from GRACE: first results, Geophys. Res. Lett., 31, L11501, doi:10.1029/2004GL019779, 2004.

Wang, C. and Yang, T.: Spatial-temporal characteristics of terrestrial water storage variation in China based on GRACE satellite data, Water Resour. Power, 31, 20-23, 2013 (in Chinese).

Wang, H., Li, D. L., and Jiang, Y. C.: Characteristics and reasons of the runoff variation in source regions of the Yellow River during 1956-2012, J. Glaciol. Geocryol., 36, 403-412, 2014 (in Chinese).

Xie, P. and Arkin, P. A.: Global precipitation: a 17-year monthly analysis based on gaugeobservations, satellite estimates, and numerical model outputs, B. Am. Meteorol. Soc., 78, 2539-2558, 1996.

Xu, M., Ye, B. S., and Zhao, Q. D.: Temporal and spatial pattern of water storage changes over the Yangtz river basin during 2002 2010 based on GRACE satellite data, Progress in Geography, 32, 68-77, 2013 (in Chinese).

Yao, X. J., Liu, S. Y., Li, L., Sun, M. P., and Luo, J.: Spatialtemporal characteristics of lake area variations in Hoh Xil region from 1970 to 2011, J. Geogr. Sci., 24, 689-702, 2014.

Yirdaw, S. Z., Snelgrove, K. R., and Agboma, C. O.: GRACE satellite observations ofterrestrial moisture changes for drought 
characterization in the Canadian Prairie, J. Hydrol., 356, 84-92, 2008.

Zeng, N., Yoon, J. H., Mariotti, A., and Swenson, S.: Variability of basin-scale terrestrial water storage from a P-E-R water budget method: the Amazon and the Mississippi, J. Climate, 21, 248$265,2008$.
Zhong, M., Duan, J. B., Xu, H. Z., Peng, P., Yan, H. M., and Zhu, Y. Z.: Trend of China land water storage redistribution at mediand large-spatial scales in recent five years by satellite gravity observations, Chinese Sci. Bull., 54, 816-821, 2009. 